Published by Al-Nahrain College of Medicine P-ISSN 1681-6579

E-ISSN 2224-4719

Email: iraqijms@colmed-alnahrain.edu.iq

http://www.colmed-alnahrain.edu.iq

http://www.iraqijms.net

Iraqi JMS 2018; Vol. 16(1)

\title{
Corneal Endotheliopathy in Pseudoexfoliation Syndrome
}

\author{
Alyaà A. Kareem ${ }^{1}$ FIBMS, CABO, FICO, Giyath Aldeen T. Neamah² FIBMS, FICO \\ ${ }^{1}$ Dept. of Surgery, College of Medicine, Kufa University, Najaf, Iraq, ${ }^{2}$ Dept. of Surgery, College of Medicine, Jaber Ibn \\ Hayan University, Najaf, Iraq
}

\begin{abstract}
Background Pseudoexfoliation syndrome is a common disorder with a wide range of ophthalmic presentation and risks. Corneal endotheliopathy is one of these presentations.

Objective To evaluate corneal endothelial cell morphology, density and function in eyes with pseudoexfoliation syndrome.

Methods $\quad 120$ eyes of sixty patients with clinically evident unilateral pseudoexfoliation were examined with non-contact specular microscopy (SP-3000P) Topcon Corporation. Central corneal thickness (T), cell density (CD), and percentage of cell hexagonality (HEX\%) were measured and the values of the affected eyes were compared to those of the fellow normal eyes. Corneas with CD less than $2000 / \mathrm{mm} 2$ or HEX\% $<50 \%$ were considered as at-risk corneas for decompensation. The pseudoexfoliated eyes were subdivided into three groups according to the density of the pseudoexfoliated material (those with deposits on the lens capsule alone, on the pupil margin alone or on both) and the morphometric values of endothelial cells in each group were studied. Statistical analysis was performed using a 2-tailed Student t-test and the Chi square test, $\mathrm{P}$ value $<0.05$ was considered significant.

Results Significant increase in central corneal thickness ( $500.25 \pm 28.95$ micron vs $493.18 \pm 28.59$ micron) and reduction in endothelial cell density $\left(2307.5 \pm 272.3\right.$ vs $\left.2480.2 \pm 289.9 \mathrm{cell} / \mathrm{mm}^{2}\right)$ with a nonsignificant decrease in cell hexagonality $(51.78 \pm 8.9$ vs $53.48 \pm 6.2 \%)$ was noticed in eyes affected by pseudoexfoliation syndrome as compared to the contralateral normal eyes. The changes were noticed more when the severity of the condition increases as reflected by the density of the pseudoexfoliated material. At risk corneas were found more frequently in eyes with pseudoexfoliation based on both endothelial cell density and cell hexagonality.

Conclusion Pseudoexfoliation syndrome is a cause of corneal endotheliopathy and a risk for corneal decompensation. More endothelial cell changes are found in eyes with advanced pseudoexfoliation. Extra care and more meticulous handling is required while operating upon eyes with pseudoexfoliation to reduce the risk for corneal decompensation.

Keywords Pseudoexfoliation, corneal endothelium, endotheliopathy, decompensation.

Citation Kareem AA, Neamah GAT. Corneal endotheliopathy in pseudoexfoliation syndrome. Iraqi JMS. 2018; Vol. 16(1): 57-65. doi: 10.22578/IJMS.16.1.9
\end{abstract}

List of abbreviations: $C D=$ cell density, $H E X \%=$ Percentage of cell hexagonality, IOP= intraocular pressure, $\mathrm{PEX}=$ Pseudoexfoliation, $\mathrm{T}$ $=$ Corneal thickness

\section{Introduction}

The pseudoexfoliation syndrome is a wide spread multisystem age related degenerative disorder of extracellular matrix, which was described as far back as 1917. In the eye a fibrilar substance, the nature of which is still not known, accumulates not only upon and within the lens capsule but also in association with the internal limiting membrane of the iris and ciliary body, upon 
their epithelial surface and around the blood vessels of the anterior uvea ${ }^{(1,2)}$.

Pseudoexfoliation affects $0.2-38 \%$ of general population at different areas around the world without sex predilection. The condition is of relevance to all comprehensive ophthalmologist because of its wide range of pathological manifestation including phacopathy, zonulopathy, cyclopathy, iridopathy, trabeculopathy and corneal endotheliopathy ${ }^{(3-5)}$.

The wide spectrum of ocular affection can result in a corresponding wide range of clinical problems and surgical complications such as glaucoma, phacodonesis, early corneal decompensation, iris rigidity and fibrosis with poor pupillary dilation together with bloodaqueous barrier disruption and pseudouveitis because of the affection of the iridial small and large blood vessels secondary to the deposition of pseudoexfoliative material. Pseudoexfoliation syndrome is a risk factor for vitreous loss during cataract extraction. Zonular instability, capsular fragility and poor quality of mydriasis account for the higher incidence of such complication ${ }^{(6-8)}$.

Local in situ production and deposition of pseudoexfoliative material is found focally in the corneal endothelium in some of the affected eyes. This explains why endothelial cell loss and decompensation take place resulting in a form of keratopathy different from that seen in conventional cases of corneal guttata (1).

A stable normal corneal endothelium has cells of relatively uniform size and shape, additionally, adequate cell density is essential to maintain corneal function. The corneal thickness measured by pachymetry is an important indicator of the corneal edema and endothelial function ${ }^{(9-13)}$.

Any pathological effect on the cornea is best illustrated by discussing changes in the endothelial morphometric parameters and corneal thickness (14). Polymegathism (increased variation in individual corneal endothelial cell areas) and pleomorphism (a decrease in the hexagonal corneal endothelial cells with concomitant increase in number of cells with more than or fewer than six sides) increase significantly in response to some ocular pathologies and may be a sign of endothelial stress ${ }^{(15)}$.

The aim of this study is to demonstrate and describe the corneal endothelium morphometric changes in eyes with pseudoexfoliation syndrome.

\section{Methods}

\section{Study design and patients' selection}

This prospective case control study was conducted on (60) patients with clinically evident unilateral pseudoexfoliation syndrome attending the ophthalmology clinic at Kufa University teaching hospital for variable ocular complaints.

The patients were eligible for the study if they have clear corneas with no evident ocular disease apart from cataract of variable density and they all shared the fact of negative past history for ocular trauma, surgery or contact lens wear. Patients with glaucoma, ocular hypertension, keratic precipitates, guttata, corneal dystrophies, corneal edema or leukomas were excluded from the study. Intraocular pressure was checked for every eye using the Goldmann applanation tonometer. All participants signed a consent form before their inclusion in this study.

\section{Workup}

Both eyes were assessed for each patient referring to the pseudoexfoliative eye as diseased eye (Group A) and the normal eye as control (Group B). Patients were considered to have pseudoexfoliation when biomicroscopic examination of the anterior segment under pupil dilation showed the characteristic grayish white pseudoexfoliative material on the anterior capsule of the lens or pupillary margin. Group A eyes were further subdivided according to the severity of the condition: eyes with deposit on the lens capsule only, on the pupil margin only or on both. Eyes with deposition on both the lens capsule and the 
pupillary margin were considered to be more severely affected than eyes that show the deposit on either site alone.

The following corneal measurements were taken for each eye in the two groups by a masked single experienced technician using the automatic noncontact specular microscopy (SP3000P, Topcon Corporation, Tokyo, Japan):

- Central corneal thickness (T) in micrometer.

- Endothelial cell density (CD), cell count per square millimeter area.

- Percent of cell hexagonality (HEX\%), the percentage of cells that have six sides in the best captured images with 60 cells or more.

At risk corneas were defined as those with hexagonal cell percent (HEX\%) less than $50 \%$ or those with endothelial cell density (CD) less than $2000 / \mathrm{mm}^{2}(9,16,17)$.

\section{Statistics}

Corneal morphometric measurements were tabulated for the two groups of eyes ( $A$ and $B$ ). The mean and standard deviation were calculated and the statistical analysis was carried on using the paired differences analysis by the student's t-test to compare eyes in groups $A$ and $B$.

The frequency of the "at risk corneas" was determined in each group and the Chi square test was used for statistical analysis.

In group A eyes, and after dividing the eyes into three subgroups depending on the site of deposit of the pseudoexfoliative material, the effect of the disease severity on the three corneal morphometric parameters was studied applying the student's t-test.

The SPSS software v.17 was used for the statistical analyses and a $P$ value less than 0.05 was considered significant.

\section{Results}

In this series of the 60 cases with unilateral pseudoexfoliation, we found:

- Male to female (M:F) ratio to be (1.2:1), 58\% of the patients were males and $48 \%$ were females.

- Mean age of the patients was (63 yr) with a range of (42-84 yr). Mean intraocular pressure (IOP) in group A (eyes with pseudoexfoliation) was $18 \mathrm{mmHg}$ and 16 $\mathrm{mmHg}$ in group $\mathrm{B}$ (normal eyes).

Table 1 summarizes the above mentioned general criteria of the studied subjects.

Mean central corneal thickness $(T)$ in microns, cell density (CD) per square millimeter and hexagonal cells percentage (HEX \%) in eyes of group $A$ and $B$ are shown in table 2 .

Figure 1 shows the corneal morphometric parameters in the two groups.

Table 3 displays the statistical analysis of the paired differences for these parameters according to the student t-test. In group A, 21 eyes out of the 60 eyes (35\%) have hexagonal cell percent less than $50 \%$ compared to 15 eyes in group B (25\%). Cell density less than $2000 / \mathrm{mm} 2$ was found in 12 eyes of group $A$ (20\%) and in 3 eyes of group B (5\%).

\section{Table 1. General criteria of the studied patients}

\begin{tabular}{cc}
\hline No. of patients & 60 \\
Male to Female ratio & $1.2: 1$ \\
Mean age of the patients & 63 years \\
Age range & $42-84$ year \\
No. of eyes with pseudoexfoliation (group A) & 60 \\
No. of normal eyes (group B) & 60 \\
Mean IOP in group A & $18 \mathrm{mmHg}$ \\
Mean IOP in group B & $16 \mathrm{mmHg}$ \\
\hline
\end{tabular}


Table 2. Specular microscopy findings in diseased and normal eyes

\begin{tabular}{cccc}
\hline \multirow{2}{*}{ Group } & \multicolumn{3}{c}{ Specular microscopy findings } \\
& $\mathbf{T}(\boldsymbol{\mu m})$ & CD $\left(\right.$ cell/ $\mathbf{m m}^{2}$ ) & HEX (\%) \\
\hline Diseased eyes (group A) & $500.25 \pm 28.95$ & $2307.5 \pm 372.38$ & $51.78 \pm 8.98$ \\
Normal eyes (group B) & $493.18 \pm 28.59^{*}$ & $2480.23 \pm 289.91^{*}$ & $53.48 \pm 6.27$ \\
\hline
\end{tabular}

Mean of corneal thickness $(T)$, cell density $(C D)$, Hexagonal cells percent $(H E X),{ }^{*}=$ significant $P$ value $(<0.05)$

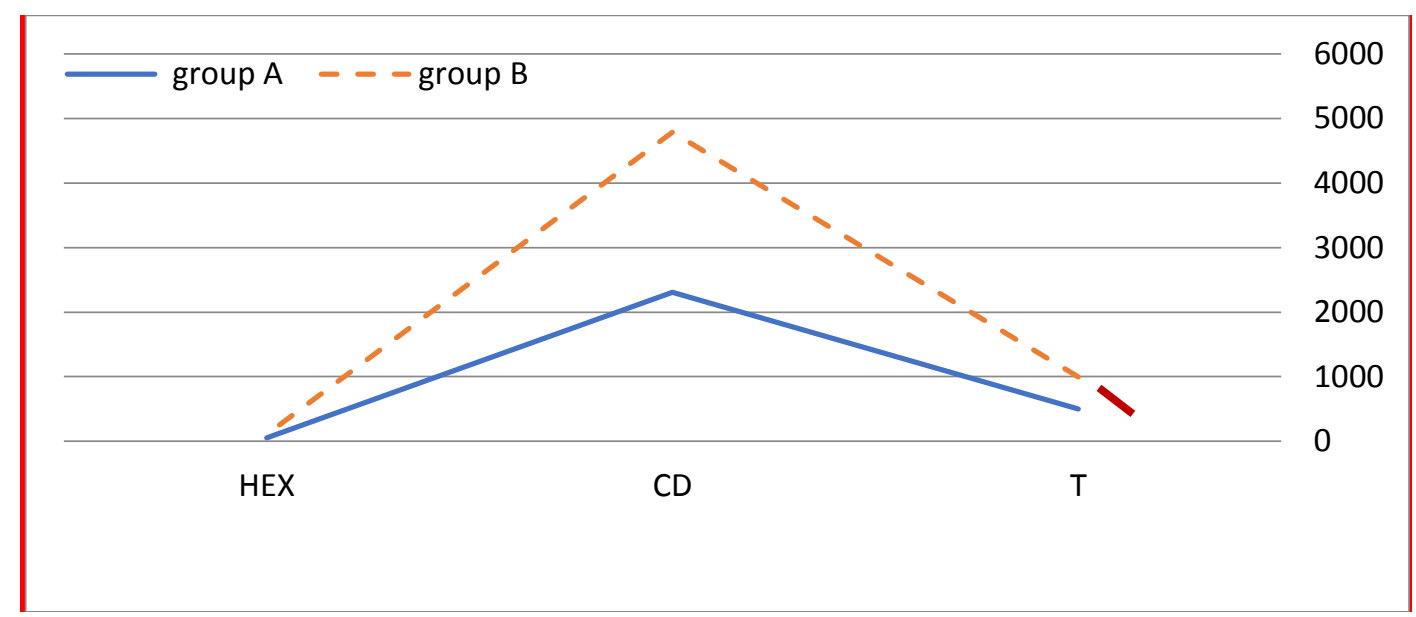

Figure 1. Comparing Specular microscopy findings in diseased (group A) and normal eyes (group B). Mean of corneal thickness (T), cell density (CD), hexagonal cells percent (HEX)

Table 3. Comparison of thickness, cell density and hexagonal cells percentage in group $A$ and group $P$ by paired ttest

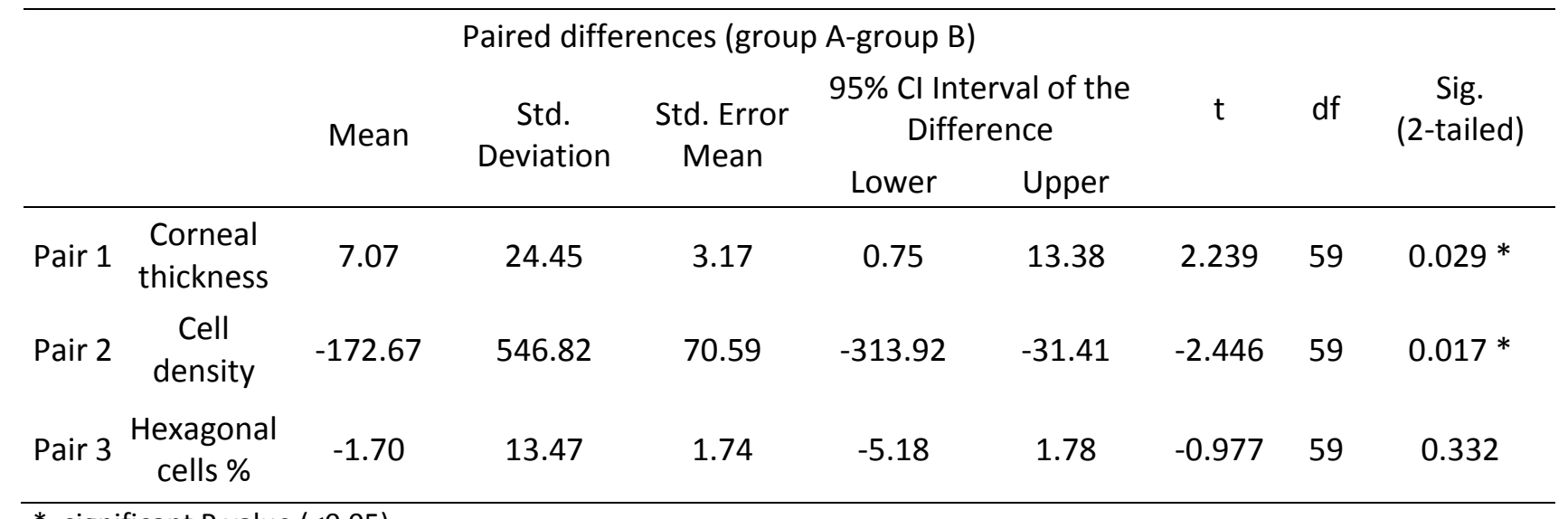

*=significant $\mathrm{P}$ value $(<0.05)$

Tables 4 and 5 show the number of "at risk corneas" in the two groups. The $P$ value was calculated according to the chi square test. The appearance of pseudoexfoliative material in group $A$ eyes was as follows:
- 15 eyes show the material on the pupilary margin only-P (25\%)

- 8 eyes had it on the anterior lens capsule only-C (13\%)

- 37 eyes had it on both the pupil and the lens capsule-P\&C (62\%) 
Table 4. Number of eyes with at risk corneas for decompensation in group A and B based on hexagonal cell percent

\begin{tabular}{cccc}
\hline Group & HEX\% $<\mathbf{5 0 \%}$ & HEX\% $\mathbf{5 0 \%}$ & Total \\
\hline A & 21 & 39 & 60 \\
B & 15 & 45 & 60 \\
\hline Total & 36 & 84 & 120 \\
\hline
\end{tabular}

$\mathrm{X} 2=1.42, \mathrm{P}$ value $>0.05$

Table 5. Number of eyes with at risk cornea for decompensation in group A and B based on endothelial cell density

\begin{tabular}{cccc}
\hline Group & CD $<\mathbf{2 0 0 0} / \mathbf{m m}^{\mathbf{2}}$ & $\mathrm{CD} \geq \mathbf{2 0 0 0} / \mathbf{m m}^{\mathbf{2}}$ & Total \\
\hline A & 12 & 48 & 60 \\
B & 3 & 57 & 60 \\
\hline Total & 15 & 105 & 120 \\
\hline
\end{tabular}

$\mathrm{X} 2=6.17, \mathrm{P}$ value $<0.05$

Figure 2 shows the distribution of the affected eyes according to the site of the deposits.

Mean of central corneal thickness $(T)$ in microns, cell density (CD) per square millimeter, hexagonal cell percent (HEX\%) in eyes with pseudoexfoliation material present on pupil only were $(487,2418,52 \%)$ respectively. In eyes with pseudoexfoliation material on capsule only the findings were (492, 2455, 55\%) and in eyes with pseudoexfoliation material on both the pupil and lens capsule they were $(507,2237,51 \%)$ respectively (Table 6 ).

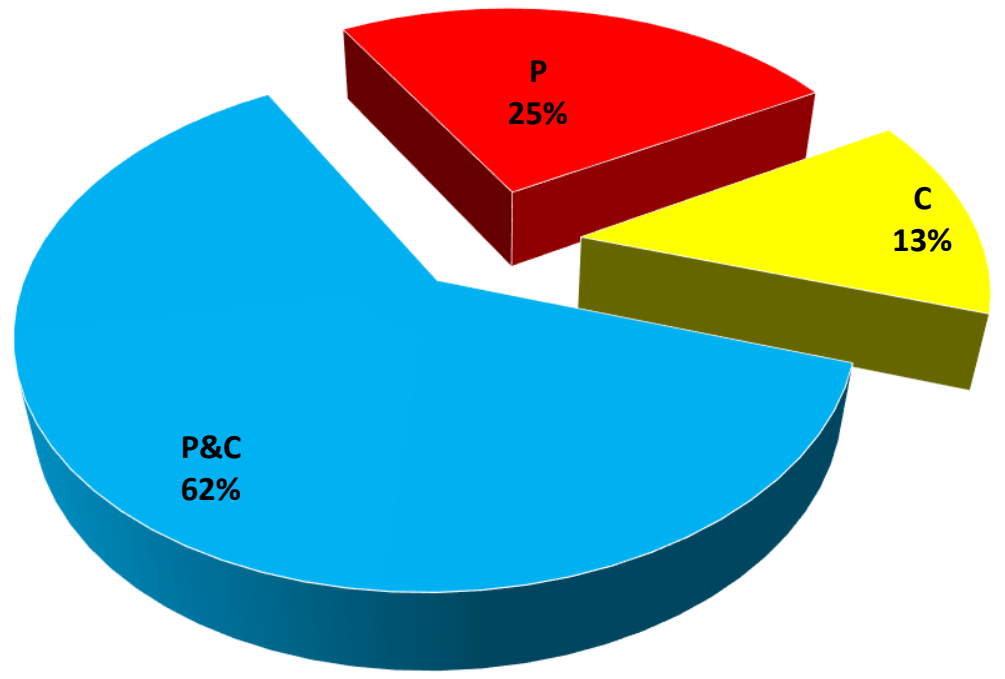

Figure 2. Distribution of eyes with pseudoexfoliation according to the site of deposit $(P=$ on the pupil margin only, $C=$ on the lens capsule only, $P \& C=$ on both the pupil and lens capsule) 
Table 6. Corneal thickness (T), endothelial cell density (CD) \& hexagonal cell percentage (HEX\%) in eyes with different severity of pseudoexfoliation (PEX)

\begin{tabular}{cccc}
\hline Parameter & $\begin{array}{c}\text { T }(\mu \mathrm{m}) \\
\text { mean } \pm \text { SD }\end{array}$ & $\begin{array}{c}\text { CD }\left(\text { cell } / \mathbf{m m}^{2}\right) \\
\text { mean } \pm \text { SD }\end{array}$ & $\begin{array}{c}\text { HEX (\%) } \\
\text { mean } \pm \text { SD }\end{array}$ \\
\hline PEX on pupil only & $488 \pm 13.86$ & $2403.73 \pm 196.38$ & $51 \pm 6.8$ \\
PEX on lens capsule only & $492.25 \pm 19.81$ & $2455 \pm 219.25$ & $55 \pm 5.63$ \\
PEX on both the pupil \&lens capsule & $506.5 \pm 35.05 *$ & $2236.8 \pm 448.29 *$ & $51.49 \pm 10.5$ \\
\hline
\end{tabular}

$(*) P<0.05$

\section{Discussion}

Pseudoexfoliation syndrome is a systemic disorder that probably results from multifocal abnormal metabolic processes of unknown etiology leading to primary cell changes and is characterized by accumulation of fibrilar material containing basement membrane components in the anterior segment of the eye and other organ systems ${ }^{(1-3)}$.

It is a frequent clinical feature seen in patients with cataract because its prevalence increases with age. In patients with pseudoexfoliation, insufficient mydriasis, in addition to zonulopathy, was determined to be the most significant risk factor for zonular breaks or rupture of the posterior lens capsule with consequent vitreous loss during extra capsular cataract extraction (4-6). Pseudoexfoliation syndrome is also known to present with corneal endotheliopathy.7 Thus, the risk for decompensation whether spontaneous or following intraocular surgery should always be thought of in eyes with this disease.

In this study, the important morphological aspects of corneal endothelial cells in patients with unilateral pseudoexfoliation were evaluated. Studying unilaterally affected eyes and comparing with the contralateral normal eyes may give more impressive information than comparing normal eyes with diseased eyes of different subjects. Such strategy minimizes the effects of all other variables in the studied subjects that might alter the results. Upon comparing the findings of the affected eyes with those of the contralateral normal eyes the following points were observed:
1- Significant reduction in endothelial cell density in eyes with pseudoexfoliation.

2- Significant increase in central corneal thickness in eyes with pseudoexfoliation.

3- The deviations from normal values increase as the density or severity of pseudoexfoliation increases in the affected eyes.

4- No significant changes were found in the shape of corneal endothelial cells in diseased eyes. Hexagonal cells percent did not vary significantly between groups.

5- At risk corneas were found more frequently in the diseased eyes than the normal eyes. Statistical analysis showed that the difference is significant if the judgment is based on endothelial cell density and nonsignificant if we consider the hexagonal cell percent.

The above findings reinforce the fact that pseudoexfoliation is a cause of corneal endotheliopathy and is a risk factor for corneal decompensation either spontaneously or in response to minor endothelial stress or surgical trauma.

The mean endothelial cell density difference between the diseased and normal eyes in this study was 127.66 cells $/ \mathrm{mm}^{2}$, which is less than the $300-500$ cells $/ \mathrm{mm}^{2}$ differences reported in the literature ${ }^{(18-21)}$. However, this difference is statistically significant with a $P$ value of 0.017 . Similarly, the 7.066 micron difference in corneal thickness between the two groups is statistically significant with a $P$ value of 0.029 compared to the 4 micron insignificant difference reported by other researchers ${ }^{(22)}$. 
Many published studies demonstrated pseudoexfoliation corneal endotheliopathy but none of them was performed on unilaterally affected patients similar to current study. However, it is valuable to summarize the results of some of these studies. Table 7 summarizes the corneal endothelial morphometric parameters found in eyes with pseudoexfoliation syndrome as compared to normal control eyes in relevant published studies.

Table 7. Summary of comparable studies on corneal endothelial morphometric parameters in eyes with or without pseudoexfoliation

\begin{tabular}{|c|c|c|c|c|c|c|c|c|c|}
\hline \multirow[b]{2}{*}{ Author } & \multirow[b]{2}{*}{ Population } & \multicolumn{2}{|c|}{ No. of eyes } & \multicolumn{3}{|c|}{ Cell density $/ \mathrm{mm}^{2}$} & \multicolumn{3}{|c|}{ HEX\% } \\
\hline & & PEX & Normal & $\begin{array}{c}\text { Eyes } \\
\text { with PEX }\end{array}$ & $\begin{array}{l}\text { Normal } \\
\text { eyes }\end{array}$ & $\begin{array}{c}P \\
\text { value }\end{array}$ & $\begin{array}{l}\text { Eyes } \\
\text { with } \\
\text { PEX }\end{array}$ & $\begin{array}{l}\text { Normal } \\
\text { eyes }\end{array}$ & $\begin{array}{c}P \\
\text { value }\end{array}$ \\
\hline Current study & Iraq & 60 & 60 & $\begin{array}{c}2307.5 \pm \\
372.38\end{array}$ & $\begin{array}{c}2480.23 \\
\pm 289.9\end{array}$ & 0.017 & $\begin{array}{c}51.78 \pm \\
8.98\end{array}$ & $\begin{array}{c}53.48 \pm \\
6.27\end{array}$ & 0.332 \\
\hline$\underset{(17)}{\text { Quiroga et al }}$ & Paraguay & 61 & 453 & $\begin{array}{c}2315 \pm 49 \\
.13\end{array}$ & $\begin{array}{c}2482 \pm 20 \\
.63\end{array}$ & 0.002 & $\begin{array}{c}56.1 \pm \\
1.06\end{array}$ & $\begin{array}{c}57.9 \pm \\
0.4\end{array}$ & 0.123 \\
\hline $\begin{array}{c}\text { Ostern \& } \\
\text { Drolsum (23) }\end{array}$ & Norway & 46 & 101 & $\begin{array}{c}2024 \pm \\
371\end{array}$ & $\begin{array}{c}2144 \pm \\
365\end{array}$ & 0.07 & $\begin{array}{c}46.4 \pm \\
10.1\end{array}$ & $\begin{array}{c}46.3 \pm \\
10.9\end{array}$ & 0.99 \\
\hline Wali et al (16) & Oman & 126 & - & $\begin{array}{l}2465.86 \\
\pm 506.68\end{array}$ & _ & & $\begin{array}{c}34.63 \pm \\
11.92\end{array}$ & - & \\
\hline
\end{tabular}

The morphological and functional parameters of central corneal endothelial cells display more deviation as the density or severity of pseudoexfoliation increases, this fact was concluded by comparing the specular microscopical findings of the diseased eyes after grouping them into three groups depending on the severity of clinically visible pseudoexfoliation material. Eyes with pseudoexfoliative material deposits on both the lens capsule and the pupil represent a more advanced presentation than those with deposits on the lens capsule alone or on the pupil alone. The more severely affected eyes have a statistically significant lower cell density and thicker corneas $(\mathrm{P}<0.05)$ but their lower percent of hexagonal cells was not significant $(P>0.05)$. Wali et al studied the effect of disease severity on corneal endothelial morphometric values by comparing eyes with pseudoexfoliation without glaucoma and those with pseudoexfoliation and glaucoma. They considered glaucoma as a reflection of an advanced stage of pseudoexfoliation. Eyes with pseudoexfoliation and glaucoma showed lower endothelial cell densities and hexagonal cell percent than non-glaucomatous eyes but the findings they reported were not significant (16). Ostern and Drolsum reported lower cell densities and percents of hexagonality in eyes with glaucoma when compared to eyes without glaucoma in a group of pseudoexfoliated eyes. Their finding was statistically non-significant ${ }^{(22)}$.

Corneas at risk for decompensation are those with tendency to decompensate when subjected to stress or trauma. Endothelial cell density less than $2000 / \mathrm{mm}^{2}$ or hexagonal cell percent $<50 \%$ are features of at risk corneas ${ }^{(9,16)}$. Corneas with such parameters were found more frequently in the pseudoexfoliated eyes than the normal eyes of our series with a statistically significant difference $(P<0.05)$ based on endothelial cell density but the difference was non-significant on the basis of reduction in hexagonal cell percent where the $P$ value was $>0.05$ (Tables 4 and 5 ). Corneas of pseudoexfoliated eyes are expected to be at risk of decompensation or compromise of their endothelial cell functions and the most 
probable cause for such deviation might be attributed to the decrease in cell count or density rather than deviation in the cell shape. These observations suggest that the corneal endothelial changes represent a consistent finding in eyes affected with pseudoexfoliation. Based on clinical and microscopic evidence, a specific corneal endotheliopathy that may be more susceptible to the effects of surgery was postulated, which is distinguishable from other forms of corneal edema. Such evidence and clinical findings point strongly to the fact that in patients with pseudoexfoliative keratopathy only moderate rises of IOP or minor intraoperative trauma might lead to a relatively early occurring diffuse corneal decompensation.

In conclusion, pseudoexfoliation is a cause for morphological changes in the corneal endothelium with a decrease in cell density that can lead to corneal decompensation. Corneal thickness is increased in pseudoexfoliative eyes with no significant pleomorphism. Denser affection by pseudoexfoliation, reflected by wider deposition of pseudoexfoliative material, shows more evident endotheliopathy.

Carful assessment for the eyes of elderly patients looking for pseudoexfoliation while preparing for intraocular surgery is recommended with special attention and care to be paid with meticulous handling during the surgery to protect the corneal endothelium. Viscoelastic substances use and avoiding instrumental touch to the endothelium are to be emphasized on to decrease the risk of corneal decompensation.

\section{Acknowledgments}

Thanks are due to the staff members of the ophthalmology department at Kufa University Teaching Hospital.

\section{Authors Contribution}

Dr. Neamah collected the data and interpreted the results with dr. Kareem who finalized the writing of the paper.

\section{Conflict of interest}

The authors have no conflict of interest to declare.

\section{Funding}

The work was completed without any funding resources.

\section{References}

1. Nauman GO. The pseudoexfoliation syndrome affects one person out of twenty over age 50 . Ophthalmol News. 1997; 17: 1-3.

2. Duke Elder SS. Pseudoexfoliation. In: Duke Elder SS, (ed). System of Ophthalmology. 3rd ed. St Louis: Mosby; 1976. p. 54-6.

3. Kareem $A A$. Mydriasis insufficiency in pseudoexfoliation syndrome. Kufa Med J. 2004; 7(1): 166-70.

4. Al Tak A. Pseudoexfoliation syndrome among eye clinic patients in Mousal Bas J Surg. 2000; 6: 51-3.

5. Miyake K, Matsuda M, Inaba M. Corneal endothelial changes in pseudoexfoliation syndrome. Am J Ophthalmol. 1989; 108(1): 49-52. doi: http://dx.doi.org/10.1016/S0002-9394 (14)73259-3.

6. Brooks AMV. Gilies WE. Fluorescein angiography and fluorometry in pseudoexfoliation syndrome. British J Ophthalmol. 1983; 67: 249-54.

7. Amund R, Martin D. Iris neovasculareization in eyes with pseudoexfoliation syndrome. British J Ophthalmol. 1981; 65: 138-41.

8. Brooks AM, Gilies WE. The development of micro neovascularization changes in the iris in pseudoexfoliation syndrome of the lens capsule. Ophthalmology. 1987; 94(9): 1090-7.

9. Kareem AA. Evaluation of corneal endothelial cells hysteresis after phacoemulsification. Kufa Med J. 2012; 15(1): 362-71.

10. Lattimore MR. Influence of extended soft contact lens wear on the comparative measurement of central corneal thickness. Acta Ophthalmol Scand 1996; 74(3): 239-42.

11. Yebra-Pimentel E, Giráldez MJ, González J, et al. Changes in corneal thickness after daily and extended wear of hydrogel lenses: a comparison of optical and ultrasonic pachometry. Int Contact Lens Clin. 1998; 25: 103-8. doi: https://doi.org/10.1016/S08928967(98)00021-2.

12. Fakhry MA, Artola A, Belda Jl, et al. Comparison of corneal pachymetry using ultrasound and Orbscan II. J Cataract Refract Surg. 2002; 28(2): 248-52.

13. Reinstein DZ, Aslanides IM, Silverman RH, et al. Highfrequency ultrasound corneal pachymetry in the assessment of corneal scars for therapeutic planning. CLAO J. 1994; 20(3): 198-203.

14. Yee RW, Matsuda M, Edelhauser HF. Wide field endothelial counting panels. Am J Ophthalmol.1985; 99(5): 596-7. 
15. Rao GN, Shaw EL, Arthur EJ, et al. Endothelial cell morphology and corneal deturgescence. Ann Ophthalmol. 1979; 11(6): 885-99.

16. Wali UK, Bialasiewicz AA, Rizvi SG, et al. In vivo morphometry of corneal endothelial cells in pseudoexfoliation keratopathy with glaucoma and cataract. Ophthalmic Res. 2009; 41(3): 175-9. doi: 10.1159/000210831.

17. Quiroga L, Lansingh VC, Samudio $M$, et al. Characteristics of the corneal endothelium and pseudoexfoliation syndrome in patients with senile cataract. Clin Exp Ophthalmol. 2010; 38(5): 449-55. doi: 10.1111/j.1442-9071.2010.02313.x.

18. Wirbelauer C, Anders N, Pham DT, et al. Corneal endothelial cell changes in pseudoexfoliation syndrome after cataract surgery. Arch Ophthalmol. 1998; 116(2): 145-9.

19. Teshome $T$, Regassa $K$. Prevalence of pseudoexfoliation in Ethiopian patients scheduled for cataract surgery. Acta Ophthalmol Scand. 2004; 82(3 Pt 1): 254-8. doi: 10.1111/j.1395-3907.2004.00263.x
20. Inoue K, Okugawa K, Oshika T, et al. Morphological study of corneal endothelium and corneal thickness in psudoexfoliation syndrome. Jpn j Ophthalmol. 2003; 47(3): 235-9.

21. Seitz B, Müller EE, Langenbucher A, et al. [Endothelial keratopathy in pseudoexfoliation syndrome; quantitative and qualitative morphometry using automated video image analysis]. Klin Monatsbl Augenheilked. 1995; 207(3): 167-75.

22. Ostern AE, Liv Drolsum L. Corneal endothelial cells 67 years following cataract surgery in patients with pseudoexfoliation syndrome. Acta Ophthalmol. 2012; 90(5): 408-11. doi: 10.1111/j.17553768.2010.02012.x.

Correspondence to Dr. Alyaà A. Kareem
E-mail: alyaaboodkareem@yahoo.com,
alyaa.alajeeli@uokufa.edu.iq
Received Apr. 27 2017
Accepted Sep. 17th 2017

